\title{
O TRABALHO DOCENTE NO ENSINO SUPERIOR EM EDUCAÇÃO FÍSICA SOB A ÓTICA DOS PESQUISADORES BRASILEIROS
}

\author{
Caroline Broch \\ Universidade Estadual de Maringá, Maringá, Paraná, Brasil. \\ Fabiane Castilho Teixeira \\ Centro Universitário de Maringá, Maringá, Paraná, Brasil. \\ Claudio Kravchychyn \\ Universidade Estadual de Maringá, Maringá, Paraná, Brasil. \\ Ieda Parra Barbosa-Rinaldi \\ Universidade Estadual de Maringá, Maringá, Paraná, Brasil.
}

\begin{abstract}
Resumo
$\mathrm{O}$ artigo objetivou investigar o trabalho docente no ensino superior em Educação Física sob a ótica dos pesquisadores brasileiros. A pesquisa caracterizou-se como revisão sistemática da literatura e buscas foram realizadas nas bases de dados Lilacs, Scielo, SportDiscus e Web of Science. A amostra foi composta por três artigos científicos. A análise descritiva e o método de análise de conteúdo subsidiaram o tratamento dos dados. As publicações destacaram preocupações com a qualificação profissional e ainda que interesses mercadológicos e precárias condições de trabalho são elementos que interferem no exercício profissional. Conclui-se que essa temática é incipiente e periférica na produção científica da área, requerendo maior empreendimento de seus pesquisadores.
\end{abstract}

Palavras-chave: Trabalho docente. Ensino superior. Educação Física.

\section{THE TEACHING WORK IN HIGHER EDUCATION IN PHYSICAL EDUCATION UNDER THE OPTICS OF BRAZILIAN RESEARCHERS}

\begin{abstract}
The article aimed to investigate the teaching work in higher education in Physical Education from the perspective of the Brazilian researchers. The research was characterized as a systematic review of the literature and searches were performed in Lilacs, Scielo, SportDiscus and Web of Science databases. The sample consisted of three scientific papers. The descriptive analysis and the method of content analysis subsidized the treatment of the data. The publications highlighted concerns about professional qualification and, furthermore, that market interests and precarious working conditions are elements that interfere with

\footnotetext{
${ }^{1}$ Financiamento: O presente trabalho contou com apoio financeiro da Coordenação de Aperfeiçoamento de Pessoal de Nível Superior (Capes) por meio da concessão de bolsa de estudo.

Conflito de Interesse: Os autores declaram não haver conflitos de interesse.

Agradecimentos: Agradecemos à Capes, pela bolsa concedida para o desenvolvimento da pesquisa.
} 
professional practice. It is concluded that this theme is incipient and peripheral in the scientific production in the area and requires greater undertaking of its researchers.

Keywords: Teaching work. Higher education. Physical Education.

\title{
EL TRABAJO DOCENTE EN LA ENSEÑANZA SUPERIOR EN EDUCACIÓN FÍSICA BAJO LA ÓPTICA DE LOS INVESTIGADORES BRASILEÑOS
}

\begin{abstract}
Resumem
El artículo objetivó investigar el trabajo docente en la enseñanza superior en Educación Física bajo la óptica de los investigadores brasileños. La investigación se caracterizó como revisión sistemática de la literatura y búsquedas se realizaron en las bases de datos Lilacs, Scielo, SportDiscus y Web of Science. La muestra se compuso de tres artículos científicos. El análisis descriptivo y el método de análisis de contenido subsidiaron el tratamiento de los datos. Las publicaciones destacaron preocupaciones con la calificación profesional y, aún, que intereses mercadológicos y precarias condiciones de trabajo son elementos que interfieren en el ejercicio profesional. Se concluye que esta temática es incipiente y periférica en la producción científica del área, requiriendo mayor emprendimiento de sus investigadores.
\end{abstract}

Palabras clave: Trabajo docente. Enseñanza superior. Educación Física.

\section{Introdução}

O empreendimento dos pesquisadores que se propõem a discutir o trabalho docente no ensino superior em Educação Física (EF) é recente. Foi a partir da expansão dos cursos de graduação e de pós-graduação na década de 1990 que tal temática se tornou um lócus de investigação.

É oportuno mencionar que o trabalho docente no ensino superior mobiliza pesquisadores no escopo de conhecimento da Educação, com destaque para as discussões sobre as modificações nos processos de trabalho e as implicações da expansão do ensino superior para o desempenho da profissão (ISAIA et al., 2006; VEIGA, 2006; BOSI, 2007; TARDIF; LESSARD, 2007; SGUISSARDI, 2008; SEVERINO, 2009; PIMENTA; ANASTASIOU, 2014; MANCEBO et al., 2015). Destacamos que nosso foco de pesquisa se volta a essa temática na área da EF.

Ao ser demarcada pela reorganização do trabalho e pela globalização, a educação brasileira sofreu pressão para que o trabalho docente fosse locado na perspectiva comercial. Sendo assim, novos desafios foram lançados aos docentes no exercício da profissão, pois os papéis e as funções do professor se transformaram junto com a sociedade (ISAIA; BOLZAN; MACIEL, 2009; AZZI, 2012; NEIRA, 2012).

Ademais, vínculos cada vez mais flexíveis se multiplicaram e refletiram em mudanças no campo do trabalho, gerando um clímax de dúvidas, riscos e incertezas. O sistema que traçava claras definições sobre o trabalho na família e o trabalho profissional e que conferia identidade e estabilidade às pessoas sofreu significativas modificações que redefiniram a organização do trabalho, da educação e da vida (BECK, 2011).

Com isso, o papel do professor universitário extrapolou as atividades de ensino. Novas atribuições surgiram como, por exemplo, o planejamento de aulas, a elaboração e correção de avaliações, o desenvolvimento de pesquisas, a participação em eventos, a orientação de trabalhos científicos, a participação em projetos de extensão, a ocupação de cargos administrativos, além de um conjunto de outras atividades pré, inter e pós-aula (VEIGA, 2006). Vislumbra-se 
uma ampliação da jornada de trabalho em que as linhas que separam o tempo de trabalho e o tempo de descanso estão cada vez mais emaranhadas (MOROSINI, 2009).

Essa nova configuração vem promovendo modificações também no trabalho docente em EF. No entanto, no campo das produções acadêmicas dessa área, tal temática foi pouco explorada (CUNHA, 2010; REZER, 2010). Os estudos já realizados voltaram-se, de forma geral, para a qualidade de vida e saúde física e mental do professor na educação básica (SANTOS, 2006; PEREIRA, 2008; WITTIZORECKI, 2009; BOTH, 2011; SILVA; SILVA, 2013; VEIGA, 2013), além de pesquisas sobre as condições de trabalho no contexto da intervenção profissional no âmbito informal (PALMA et al., 2009; MENDES, 2010; FURTADO; SANTIAGO, 2015).

A literatura sobre o trabalho docente no ensino superior em EF é escassa, evidenciando lacunas na produção científica e, portanto, requerem maiores esforços investigativos. Considerando esses argumentos introdutórios, o objetivo do artigo foi investigar o trabalho docente no ensino superior em EF sob a ótica dos pesquisadores brasileiros.

\section{Decisões metodológicas}

A opção metodológica foi pela revisão sistemática da literatura, por se tratar de um meio rigoroso de sintetizar o conhecimento da literatura relevante sobre uma temática específica, além de indicar temas que carecem de maior empreendimento investigativo (THOMAS; NELSON; SILVERMAN, 2012).

A fim de sistematizar a coleta de dados, foi elaborada uma ficha de pesquisa com base nas indicações do Preferred Reporting Items for Systematic reviews and Meta-Analyses (PRISMA), especificamente o PRISMA-P (MOHER et al., 2009). O seu objetivo foi validar o problema e o objetivo da pesquisa, definir os critérios de inclusão e exclusão, bem como o rigor metodológico a ser seguido.

A busca dos artigos foi efetuada nas bases de dados eletrônicas Lilacs, Scielo, Sport Information Resource Centre (SportDiscus) e Web of Science. Consultamos o DECs (descritores de assunto em Ciências da Saúde da BIREME). Para eleger os descritores utilizados no levantamento dos estudos, empregamos os seguintes: "higher education", "teachers'work", e "physical education". E para complementar a busca, utilizamos os termos: "trabalho docente", "docência universitária", "carreira docente", "docência", "professor", "ensino superior" e "educação física". Os operadores booleanos "AND" e "OR" foram empregados para conectar os termos de busca e definir a relação entre eles.

O recorte temporal a partir de 2000 foi definido considerando que é a partir dessa data que ocorre maior apropriação e produção de conhecimento sobre trabalho docente na área da EF. Para delimitar o universo da pesquisa, os seguintes critérios de inclusão foram aplicados: a) artigos científicos publicados no período de 2000 a 2017; b) pesquisas publicadas no Brasil; c) artigos publicados em periódicos da EF. E, por sua vez, os critérios de exclusão: a) estudos de revisão de literatura/bibliográfica (revisão sistemática, revisão narrativa, revisão integrativa, estado da arte), resenhas, ensaios, carta de opinião e carta ao editor; b) artigos que tratam da docência no âmbito universitário, mas que não abordam substancialmente o trabalho docente no ensino superior em EF.

Seguindo o protocolo de coleta de dados, a busca efetuada nas bases de dados localizou 221 artigos científicos (Scielo: $n=88$; Lilacs: $n=85$; Web of Science: $n=30$; Sportdiscus: $\mathrm{n}=18$ ). Na sequência, foi realizada a leitura dos títulos, resumos e palavras-chave, restando 15 publicações para leitura na íntegra, distribuídas da seguinte forma: (Lilacs: n=7; Scielo: n=5; Web of Science: $n=2$; Sportdiscus: $n=1$ ). Após a leitura na íntegra dos 15 artigos, foram elei- 
tas cinco produções que contemplaram a temática do estudo e se adequaram aos critérios préestabelecidos. Verificamos que dois artigos estavam duplicados, o que resultou em três artigos para análise final.

Para a categorização das contribuições das produções em análise, recorremos ao método de análise de conteúdo (BARDIN, 2011), eleito por recorrer a procedimentos sistemáticos e objetivos da descrição de conteúdos de mensagens, além de possibilitar uma leitura e análise mais profunda dos conteúdos verificados.

\section{Resultados e discussões}

Como parte inicial da análise, apresentamos, na sequência, a organização do fluxograma da revisão sistemática.

Figura 1: Fluxograma com as etapas da revisão sistemática.

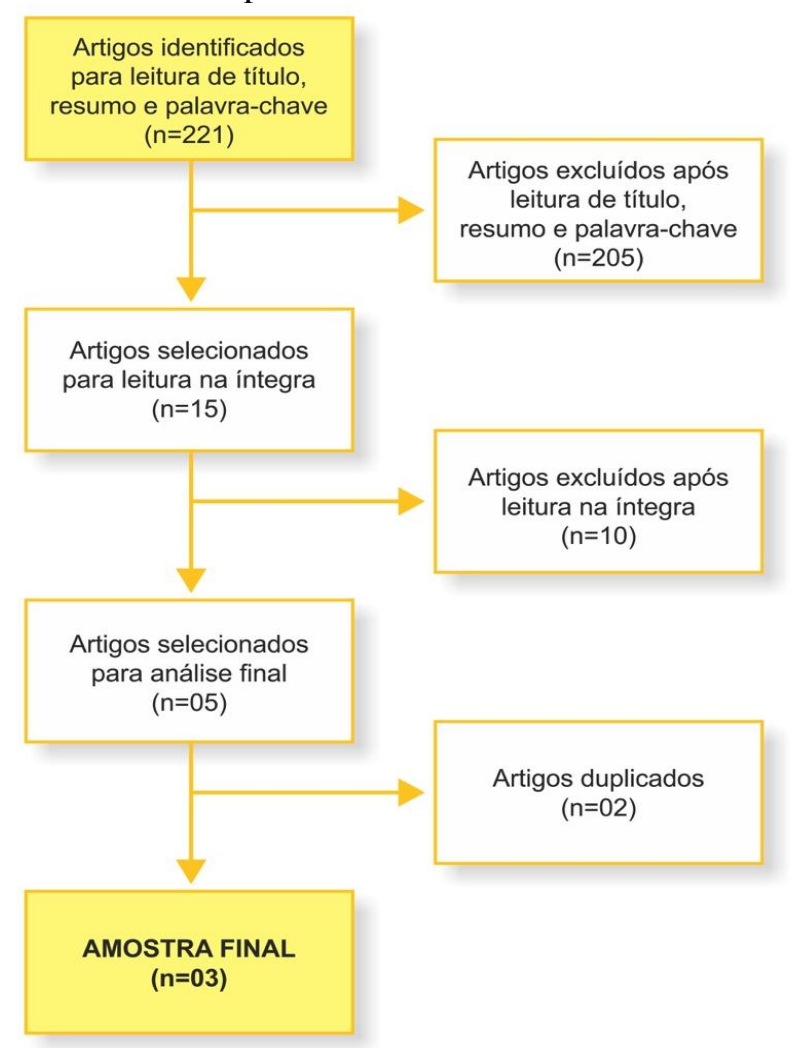

Fonte: Os autores.

Após a identificação dos três artigos eleitos para análise final desse estudo, foi feita uma verificação da lista de referências indicada em cada um dos artigos, a fim de conferir se haveria outros que não foram recuperados nas bases de dados e que contemplassem o foco da pesquisa. Entretanto, nenhuma produção foi encontrada.

Em um segundo momento da análise, foram extraídos e sintetizados os seguintes dados: título, autor e ano, objetivo, metodologia (tipo de pesquisa, fonte de dados) e principais resultados. Depois, organizada a síntese das produções científicas com a demonstração dos principais resultados que trataram da temática: trabalho docente no ensino superior em EF, estruturada com base nos critérios estabelecidos (Quadro 1). 
Quadro 1: Síntese das produções científicas sobre trabalho docente no ensino superior em EF.

\begin{tabular}{|c|c|c|c|c|}
\hline Título & Autor / Ano & Objetivo & Metodologia & Principais Resultados \\
\hline $\begin{array}{l}\text { O discurso real } \\
\text { e o discurso } \\
\text { ideal de } \\
\text { professores de } \\
\text { Educação } \\
\text { Física do } \\
\text { ensino superior } \\
\text { sobre docência }\end{array}$ & $\begin{array}{l}\text { SILVA, R. da S.; } \\
\text { ANDRADE, A.; } \\
\text { ZANELLI, J. C. / } \\
2010\end{array}$ & $\begin{array}{l}\text { Analisar a } \\
\text { relação entre } \\
\text { o discurso } \\
\text { real e o } \\
\text { discurso } \\
\text { ideal de } \\
\text { professores } \\
\text { de Educação } \\
\text { Física sobre } \\
\text { docência, } \\
\text { oriundos das } \\
\text { universidades } \\
\text { públicas de } \\
\text { SC. }\end{array}$ & $\begin{array}{c}\text { Pesquisa } \\
\text { descritiva. } \\
\text { Entrevistas } \\
\text { semiestruturadas. } \\
\text { Questionários. }\end{array}$ & $\begin{array}{l}\text { - Interesses mercadológicos } \\
\text { no exercício profissional } \\
\text { geram: competitividade; } \\
\text { individualismo; produtivismo; } \\
\text { declínio do status; } \\
\text { - Aspectos que afastam o } \\
\text { discurso real e o ideal: tipo de } \\
\text { formação; fundamentação } \\
\text { fraca; exigências } \\
\text { institucionais; dicotomia } \\
\text { teoria e prática. } \\
\text { - Aspectos que aproximam o } \\
\text { discurso real e o ideal: } \\
\text { superações ao entendimento } \\
\text { de saúde; bases legais da } \\
\text { atuação docente; papel do } \\
\text { discurso na formação. }\end{array}$ \\
\hline $\begin{array}{c}\text { Trabalho } \\
\text { docente na } \\
\text { educação } \\
\text { superior - } \\
\text { reflexões } \\
\text { epistemológicas } \\
\text { no campo da } \\
\text { Educação } \\
\text { Física... }\end{array}$ & $\begin{array}{c}\text { REZER, R.; } \\
\text { NASCIMENTO, J. } \\
\text { V.; } \\
\text { FENSTERSEIFER, } \\
\text { P. E.; GRAÇA, A. } \\
\text { B. dos S. / } 2012\end{array}$ & $\begin{array}{c}\text { Refletir } \\
\text { acerca do } \\
\text { trabalho } \\
\text { docente na } \\
\text { Educação } \\
\text { Superior, } \\
\text { tendo por } \\
\text { referência o } \\
\text { campo da } \\
\text { EF. }\end{array}$ & $\begin{array}{c}\text { Pesquisa } \\
\text { descritiva. } \\
\text { Entrevistas } \\
\text { semiestruturadas. }\end{array}$ & $\begin{array}{l}\text { - Pequena produção científica } \\
\text { sobre trabalho docente no } \\
\text { ensino superior em EF; } \\
\text { - A universidade não } \\
\text { problematiza a si mesma e } \\
\text { silêncio dos professores de EF } \\
\text { sobre seu próprio trabalho; } \\
\text { - Motivos de } \\
\text { desencantamento docente: } \\
\text { exigência por produção } \\
\text { científica; envolvimento com } \\
\text { outras funções além da } \\
\text { docência; ausência de } \\
\text { reflexão; ações } \\
\text { individualizadas. }\end{array}$ \\
\hline $\begin{array}{c}\text { Função docente } \\
\text { no ensino } \\
\text { superior: } \\
\text { discussão } \\
\text { parcial para } \\
\text { uma proposta } \\
\text { de formação } \\
\text { continuada de } \\
\text { docentes } \\
\text { universitários }\end{array}$ & $\begin{array}{l}\text { BORGES, C. N. F.; } \\
\text { CRUZ JUNIOR, } \\
\text { A. F. da.; FONTE, } \\
\text { S. S. D. / } 2012\end{array}$ & $\begin{array}{l}\text { Discutir a } \\
\text { função } \\
\text { docente no } \\
\text { ensino } \\
\text { superior, a } \\
\text { partir de um } \\
\text { estudo maior } \\
\text { realizado } \\
\text { sobre o } \\
\text { projeto Vem } \\
\text { Com a Gente }\end{array}$ & $\begin{array}{c}\text { Pesquisa } \\
\text { descritiva. } \\
\text { Entrevistas } \\
\text { semiestruturadas. }\end{array}$ & $\begin{array}{l}\text { - Docentes de IES pública têm } \\
\text { maior envolvimento com } \\
\text { ensino, pesquisa, extensão, e } \\
\text { acesso à Formação } \\
\text { Continuada; } \\
\text { - Necessidade de oportunizar } \\
\text { condições objetivas de acesso } \\
\text { a Formação Continuada para } \\
\text { docentes de IES privadas; } \\
\text { - Formação continuada como } \\
\text { possibilidade de formação } \\
\text { política para nortear a prática. }\end{array}$ \\
\hline
\end{tabular}

Fonte: os autores.

Na perspectiva de caracterização das produções científicas que constituíram a amostra final desse estudo, identificamos que dois artigos são recortes de pesquisas de doutorado (SILVA; ANDRADE; ZANELLI, 2010; REZER, et al., 2012); e o outro artigo trata-se de uma experiência realizada na Universidade Federal do Espírito Santo, com projeto de formação continuada (BORGES et al., 2012). Destaca-se a vinculação dos resultados de estudos 
decorrentes de programas de pós-graduação e sua disseminação nos periódicos científicos (LAZZAROTTI FILHO et al., 2012).

As pesquisas em análise foram divulgadas entre os anos de 2010 e 2012, as quais investigaram professores universitários de IES públicas e privadas. Além disso, identificamos que todos os autores optaram pelo método de pesquisa descritiva. No que se refere ao emprego de instrumentos de coleta de dados, observamos a prevalência de entrevistas semiestruturadas, sendo que um dos estudos também fez uso da aplicação de questionários. É oportuno destacar que recursos como entrevistas, questionários, observações sistemáticas estão entre as alternativas comumente eleitas por pesquisadores da área sociocultural.

Outra observação oportuna é que os resultados aqui apresentados sugerem a confirmação da lacuna na produção científica que trata do trabalho docente no ensino superior em EF. Uma das hipóteses para o diagnóstico dessa tímida produção é o fato de a universidade refletir pouco sobre o seu próprio contexto, conjeturando um cenário em que a produção acadêmica gestada na pós-graduação em EF enfoca mais o trabalho docente em diferentes âmbitos e campos de intervenção do que no contex to universitário (REZER, 2010).

Prosseguindo a análise, a discussão dos principais resultados sobre o trabalho docente foi organizada em duas categorias e suas respectivas subcategorias, conforme apresentamos na Figura 2.

Figura 2: Categorização dos principais resultados encontrados nas pesquisas.

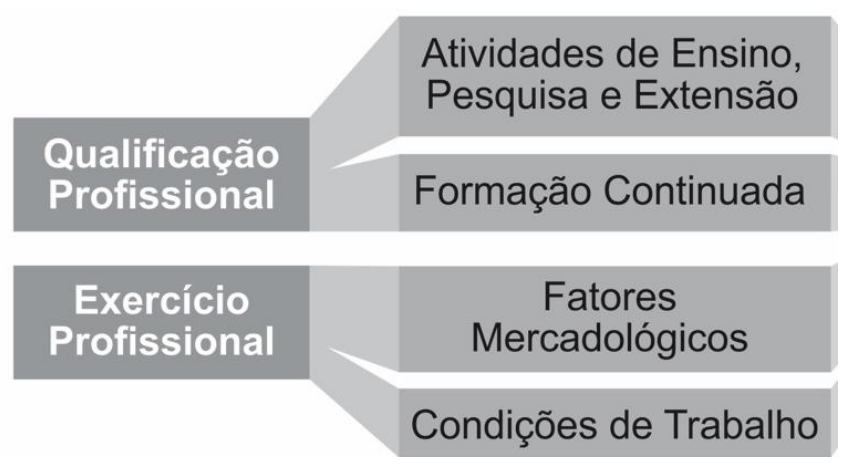

Fonte: Os autores.

A partir dos resultados da pesquisa, identificamos um conjunto de temáticas sobre trabalho docente, as quais foram contempladas em duas categorias de análise, a saber: $1^{\circ}$ qualificação profissional e as implicações no trabalho docente; e $2^{\circ}$ exercício profissional do docente no ensino superior.

Qualificação Profissional: Implicações No Trabalho Docente

Essa categoria contemplou as subcategorias de análise: "atividades de ensino, pesquisa e extensão" e "formação continuada". Para esta discussão, vale pontuar a crescente preocupação com a qualidade no ensino superior, especialmente, em decorrência da ampliação de Instituições de Ensino Superior (IES) públicas e privadas. Isso se dá, pois, muitas vezes, o aumento da oferta no ensino superior não apresenta relação com a melhoria na qualidade do ensino e com a formação de profissionais, o que pode repercutir em prejuízos para o processo de ensino-aprendizagem (TEMP et al., 2015).

Em relação às "atividades de ensino, pesquisa e extensão", o estudo de Borges et al. (2012) indica que as IES públicas e privadas se caracterizam como espaços distintos, com organizações próprias. Enquanto nas instituições públicas há incentivo para que o professor se envolva com as atividades de ensino, pesquisa e extensão - tripé da universidade - nas institu- 
ições privadas, o envolvimento dos docentes é praticamente exclusivo com as atividades de ensino.

Por isso, os autores destacam a escassez de fomento à pesquisa e à extensão nas IES privadas, bem como à formação continuada dos docentes. Por outro lado, Borges et al. (2012) afirmam que, independentemente do vínculo, é necessário que o professor se comprometa com a produção do conhecimento, mesmo que as políticas das instituições privadas não incentivem o trabalho perspectivado no tripé universitário.

É oportuno mencionar que o professor que atua em IES privada, na maioria das vezes, é pago pelas horas trabalhadas em sala de aula e, por isso, precisa dispor de carga horária semanal elevada em sala de aula, tendo em vista seu rendimento salarial. Além disso, ele é cobrado pelo cumprimento das tarefas burocráticas, o que pode dificultar sobremaneira o envolvimento com outras atividades.

Já a pesquisa de Silva et al. (2010), ao analisar a docência a partir do discurso de professores de IES públicas, demonstrou que as condições estruturais, como falta de estrutura técnico-administrativa, de espaço físico e de laboratórios, comprometem a qualidade do trabalho do docente com as atividades de ensino, pesquisa e extensão. A situação retratada corroborou o exposto por Tardif e Lessard (2007) ao destacarem que a precariedade das condições estruturais e a escassez de recursos financeiros impactam sobremaneira no trabalho docente.

No que se refere à subcategoria "formação continuada", Borges et al. (2012) destacam que essa formação deve ser incentivada, propiciando reflexões também no viés político, por meio de uma postura autônoma, crítica e reflexiva. Na mesma linha de pensamento, Rezer et al. (2012) consideram que a formação continuada oferece condições objetivas de operar de forma autônoma no mundo profissional, desenvolvendo a capacidade crítica de discernimento para a construção da carreira.

Pimenta e Anastasiou (2014) trouxeram à tona a discussão sobre a formação pedagógica dos professores. Afirmaram que a maioria dos docentes de IES não possui formação pedagógica adequada para a prática do ensino, sendo necessário que esses profissionais procurem auxílio, por meio da Formação Continuada, para tornar suas aulas mais motivadoras e próximas à realidade vigente.

Nessa direção, Basei (2012) argumentou que a docência no ensino superior exige dos profissionais competências e habilidades específicas que não se restringem à titulação de mestre ou de doutor; exige um domínio de conhecimentos específicos da área, a consciência crítica para questionar e contextualizar esses conhecimentos e para construir outros, proporcionando processos de aprendizagem, muito mais que o ensino, transcendendo assim a mera reprodução e repasse de informações.

Aliás, a qualificação docente requer que a formação continuada e o desenvolvimento profissional ocorram de forma ininterrupta e unificada. Daí a importância das IES ofertarem programas de formação continuada aos seus docentes, no sentido de potencializar o bom desempenho em sala de aula e aproximar as atividades científicas das pedagógicas (PIMENTA; ANASTASIOU, 2014; TEMP et al., 2015).

As considerações até aqui apresentadas destacaram que a qualificação profissional apresenta implicações para a prática docente. Aliás, as condições de trabalho permeiam a segunda categoria de análise da pesquisa, na sequência apresentada.

\section{Exercício Profissional Do Docente No Ensino Superior}

O exercício profissional do docente no ensino superior considerou as seguintes subcategorias: "fatores mercadológicos" e "condições de trabalho". Nesse sentido, vale destacar que a produção científica discute a intervenção pedagógica no contexto escolar e nas acade- 
mias e clubes. Entretanto, também é importante refletir a prática docente no contexto do ensino superior (REZER; FENSTERSEIFER, 2008).

Os achados empíricos das pesquisas analisadas dão pistas de que os interesses mercadológicos têm interferido no exercício da docência. Diante disso, a subcategoria "fatores mercadológicos" aponta o entrelaçamento das seguintes temáticas: o produtivismo, a competitividade, a individualização do trabalho docente e o status profissional. Silva et al. (2010), Rezer et al. (2012), e Borges et al. (2012) indicaram que o ambiente acadêmico vem sendo marcado pelo produtivismo, competitividade e individualismo. Destacam também que esses fatores são provocados, sobretudo, pela introdução da lógica de mercado na lógica de produção de conhecimento.

Nessa conjuntura, as universidades são pressionadas a contribuir com a competitividade da economia, adequando-se às novas demandas do modelo econômico e introduzindo à mercadorização do trabalho docente (COUTINHO et al., 2011; AZEVEDO, 2015). O produtivismo modifica radicalmente a natureza institucional e docente, afetando a maioria das áreas de formação (SGUISSARDI, 2015) e, entre elas, a Educação Física (SILVA et al., 2010).

Relatos dos pesquisados de Silva et al. (2010) e de Rezer et al. (2012) afirmaram que a exigência cada vez maior de produtividade tem refletido em um ambiente altamente competitivo, que institui guetos acadêmicos e dificulta o crescimento coletivo. Para Mancebo (2013), é tempo de se refletir com maior criticidade e seriedade sobre o tema.

Em se tratando da individualização do trabalho docente, os sujeitos investigados por Silva et al (2010) e Rezer et al. (2012) afirmaram que o volume de trabalho cada vez maior tende a deixar o trabalho do professor mais solitário. Esse processo de individualização das ações corrobora para que o diálogo entre os docentes seja pouco praticado e dificulta a articulação dos trabalhos desenvolvidos.

Outro aspecto que parece implicar no trabalho docente diz respeito ao status profissional. Em consonância com Silva et al. (2010), o status está relacionado aos aspectos econômicos (salário) e sociais (valorização social) e, apesar de ser considerado uma condição favorável ao trabalho docente, ele encontra-se fragilizado (TARDIF; LESSARD, 2007). A propósito, a fragilização do status acadêmico ocorre pela desvalorização profissional, sobretudo pelo declínio salarial que impõe condições que dificultam o desempenho dos professores universitários.

A partir disso, é possível perceber que o trabalho docente não pode ser pensado isoladamente, desconexo às transformações que ocorrem em outros setores econômicos. $\mathrm{O}$ âmbito educacional tem sido impactado por critérios de eficiência e eficácia, que estabelecem um conjunto de mudanças no sistema de ensino e invariavelmente incidem no cotidiano de trabalho dos professores universitários (FERENC et al., 2015).

A discussão em torno da subcategoria "condições de trabalho" apareceu associada aos temas: demanda de trabalho e carga horária. Com a expansão das instituições privadas de ensino, houve um aumento numérico da empregabilidade de professores do ensino superior, que acarretou na desvalorização profissional, na diminuição dos salários e no aumento da demanda de trabalho (PIMENTA; ANASTASIOU, 2014).

Esse cenário destaca a insatisfação com a demanda excessiva de trabalho. Em muitos casos, essa condição provoca um desconforto e uma sensação de angústia frente à impossibilidade de dar conta adequadamente de todas as demandas docentes (SILVA et al., 2010; REZER et al., 2012; e BORGES et al., 2012). O número de disciplinas ministradas, o tipo de vínculo empregatício, a diversidade de outras tarefas, além do ensino (supervisão, orientação, planejamento de aulas), são importantes fatores que precisam ser considerados nas condições laborais da docência universitária (TARDIF; LESSARD, 2007). 
Quanto à carga horária de trabalho - que pode ser caracterizada em tempo integral, parcial e horista - prevaleceu em IES privadas o tipo de contratação horista e nas IES públicas as carreiras são mais consolidadas e estáveis (SILVA et al., 2010; BORGES et al., 2012).

Em síntese, cada vez mais o trabalho do professor tem se expandido para além do campo pedagógico, uma vez que os docentes vivenciam um processo de intensificação e precarização de seu trabalho, com consequente enfraquecimento de sua autonomia (FERENC et al., 2015).

Os autores supracitados reforçaram que a minimização de investimentos na educação resultou em condições precárias de efetivação do trabalho docente, em termos de salário, prestígio social, satisfação pessoal e profissional. Com essa configuração, os docentes acabam se tornando reféns da falta de tempo para preparar e refletir de forma crítica o seu trabalho.

\section{Considerações Finais}

Diante da complexidade e dos desafios que envolvem o trabalho docente na atualidade, essa pesquisa objetivou investigar o trabalho docente no ensino superior em Educação Física sob a ótica dos pesquisadores brasileiros. Uma primeira constatação foi a de que o trabalho docente se caracterizou como um tema periférico na produção científica em EF.

Em síntese, as análises permitiram traçar importantes considerações:

- As pesquisas identificadas demonstraram preocupação com aspectos que perpassam a qualificação profissional, especialmente o engajamento dos docentes com as atividades de ensino, pesquisa e extensão, muitas vezes desempenhadas de forma fragmentada, em decorrência das especificidades das IES pública e privada. Há, também, embates vivenciados por docentes, sobretudo de IES privada, quanto às limitações de acesso e incentivo à formação continuada.

- As análises dos estudos revelaram um olhar crítico sobre a temática, enfatizando o vínculo entre os aspectos que permeiam o exercício da docência universitária com os interesses mercadológicos, o que resulta na precarização das condições de trabalho docente.

- A problematização sobre o trabalho docente tem sido insatisfatória na EF, sendo necessária a ampliação do processo de reflexão, tanto da área como de seus docentes sobre seu próprio trabalho.

Com as constantes modificações políticas, econômicas e sociais que afetaram diretamente as condições de trabalho docente, é imprescindível que o trabalho do professor universitário também se torne pauta de reflexão, discussão e produção científica na universidade.

Esse levantamento inicial identificou lacunas na produção de conhecimento sobre o trabalho docente em EF, uma vez que se confirma a recente preocupação da área com esta temática. Paralelamente, as produções em análise trazem importantes apontamentos sobre a atual configuração do trabalho universitário na área, que merecem ser consideradas e problematizadas com maior abrangência no cenário nacional. Nesse sentido, destacamos a necessidade da ampliação da produção acadêmico-científica em EF sobre o trabalho docente no ensino superior. 


\section{Referências}

AZEVEDO, M. L. N. Transnacionalização e mercadorização da educação superior: examinando alguns efeitos colaterais do capitalismo acadêmico (sem riscos) no Brasil - a expansão privado-mercantil. Revista Internacional de Educação Superior, Campinas/SP, v. 1, n. 1, p. 86-102, jul./set., 2015.

AZZI, S. Trabalho docente: autonomia didática e construção do saber pedagógico. In: PIMENTA, S. G. Saberes pedagógicos e atividade docente, São Paulo, Cortez, 2012.

BARDIN, L. Análise de conteúdo. Lisboa, Edições 70, edição n. 4, 2011.

BASEI, A. P. O desenvolvimento profissional e a construção da identidade do professor de educação física do ensino superior. Revista Mackenzie de Educação Física e Esporte, São Paulo, v. 11, n. 1, p. 44-60, 2012.

BECK, U. Sociedade de risco: rumo a uma outra modernidade. São Paulo, Editora 34, 2011.

BORGES, C. N. F.; et al. Função docente no ensino superior: discussão parcial para uma proposta de formação continuada de docentes universitários. Revista Pensar a Prática, Goiânia, v. 15, n. 2, p. 272-550, abr./jun., 2012.

BOSI, A. de P. A precarização do trabalho docente nas instituições de ensino superior no Brasil nesses últimos 25 anos. Revista Educação \& Sociedade, Campinas, v. 28, n. 101, p. 1503-1523, set./dez., 2007.

BOTH, J. Bem estar do trabalhador docente em educação física da região sul do Brasil. 2011. Tese (Doutorado em Educação Física) - Universidade Federal de Santa Catarina, UFSC, Santa Catarina, 2011.

COUTINHO, M. C.; MAGRO, M. L. P. D.; BUDDE, C. Entre o prazer e o sofrimento: um estudo sobre os sentidos do trabalho para professores universitários. Psicologia: teoria e prática, São Paulo, v. 13, n. 2, p. 154-167, ago., 2011.

CUNHA, F. J. P. Precarização do trabalho e educação física: situando a questão. Revista Motrivivência, Florianópolis, n. 35, ano XXII, p. 113-129, dez., 2010.

FERENC, A. V. F.; BRANDÃO, A. C. P.; BRAÚNA, R. de C. de A. Condições de trabalho docente em uma universidade pública. Revista Eletrônica Pesquiseduca, Santos, v. 07, n. 14, p. 358-384, jul.-dez. 2015.

FURTADO, R. P.; SANTIAGO, L. P. Educação física e trabalho: considerações a respeito da inserção profissional de egressos da FEF-UFG. Revista Brasileira de Educação Física e Esporte, São Paulo, v. 29, n. 2, p. 325-336, ab./jun. 2015.

ISAIA, S. M. A. Desafios à docência superior pressupostos a considerar. In: RISTOFF, D.; SEVEGNANI, P. (Org.). Docência na educação superior. INEP: Instituto Nacional de Estudos e Pesquisas Educacionais Anísio Teixeira. Coleção Educação Superior em Debate, v. 5, 2006. p. 63-84. 
ISAIA, S. M. de A.; BOLZAN, D. P. V.; MACIEL, A. M. da R. (Orgs.). Pedagogia universitária: tecendo redes sobre a educação superior. Santa Maria, Ed. Da UFSM, 2009.

LAZZAROTTI FILHO, A. et al. Modus operandi da produção científica da educação física: uma análise das revistas e suas veiculações. Revista de Educação Física/UEM, Maringá, v. 23, n. 1, p. 1-14, 1. trim., 2012.

MANCEBO, D. Trabalho docente e produção de conhecimento. Revista Psicologia e Sociedade, Minas Gerais, n. 25, v. 3, p. 519-526, 2013.

MANCEBO, D. et al. Políticas de expansão da educação superior no Brasil: 1995-2010. Revista Brasileira de Educação, Rio de Janeiro, v. 20, n. 60, jan./mar., p. 31-50, 2015.

MOROSINI, M. C. Docência e internacionalização da educação superior. In: ISAIA, S. M. de A.; BOLZAN, D. P. V.; MACIEL, A. M. da R. (Orgs.). Pedagogia universitária: tecendo redes sobre a educação superior. Santa Maria, Ed. Da UFSM, 2009.

NEIRA, M. G. Alternativas existem! Análise da produção científica em dois periódicos brasileiros sobre a docência na Educação Física. Revista Movimento, Porto Alegre, v. 18, n. 1, p. 241-257, jan./mar., 2012.

PALMA, A. et al. Nível de ruído no ambiente de trabalho do professor de educação física em aulas de ciclismo indoor. Revista de Saúde Pública, São Paulo, v. 43, n. 2, p. 345-351, 2009.

PEREIRA, É. F. Qualidade de vida e condições de trabalho de professores de educação básica do município de Florianópolis - SC. 2008. Dissertação (Mestrado em Educação Física) - Universidade Federal de Santa Catarina, UFSC, Florianópolis, 2008.

PIMENTA, S. G.; ANASTASIOU, L. G. C. Docência no Ensino Superior. $5^{\text {a }}$ ed. São Paulo: Cortez, 2014.

REZER, R.; FENSTERSEIFER, P. E. Docência em educação física: reflexões acerca de sua complexidade. Pensar a Prática, Goiânia, v. 11, n. 3. p. 319-329, 2008.

REZER, R. O trabalho docente na formação inicial em Educação Física: reflexões epistemológicas. 2010. Tese (Doutorado em Educação Física) - Universidade Federal de Santa Catarina, UFCS, Florianópolis, 2010.

REZER, R.; NASCIMENTO, J. V. FENSTERSEIFER, P. E.; GRAÇA, A. B. S. Trabalho docente na educação superior - reflexões epistemológicas no campo da educação física. Revista Brasileira de Ciências do Esporte, Florianópolis, v. 34, n. 4, p. 891-908, out./dez., 2012.

SANTOS, J. F. S. Atividade física, saúde mental e percepção de condições de trabalho dos professores da rede municipal de ensino de Joinville. 2006. Dissertação (Mestrado em Educação Física) - Universidade Federal de Santa Catarina, UFSC, Florianópolis, 2006.

SEVERINO, A. J. Expansão do ensino superior: contextos, desafios, possibilidades. Avaliação, Campinas. v. 14, n. 2, p. 253-266, jul., 2009. 
SGUISSARDI, V. Modelo de expansão da educação superior no Brasil: predomínio privado/mercantil e desafios para a regulação e a formação universitária. Educação Social, Campinas, v. 29, n. 105, p. 991-1022, 2008.

SGUISSARDI, V. Educação superior no Brasil: democratização ou massificação mercantil? Educação e Sociedade, Campinas, v. 36, n. 133, p. 867-889. out./dez., 2015.

SILVA, R. da; et al. O discurso real e o discurso ideal de professores de educação física do ensino superior sobre docência. Revista Movimento, Porto Alegre. v. 16, n. 3, p. 133-154, jul./set., 2010.

SILVA, L. G. da SILVA, M. C. da. Condições de trabalho e saúde de professores préescolares da rede pública de ensino de Pelotas. Revista Ciência e Saúde Coletiva, Rio de Janeiro, n. 18, v. 11, p. 3137-3146, 2013.

TARDIF, M.; LESSARD, C. O trabalho docente: elementos para uma teoria da docência como profissão de interações humanas. Petrópolis, RJ, Vozes, 2007.

TEMP, H.; et al. Formação Continuada no ensino superior: um estudo com professores que atuam em cursos de educação física. Revista Eletrônica Pesquisaeduca, Santos, v. 7, n.14, p. 406-433, jul./dez., 2015.

THOMAS, J. R.; NELSON, J. K.; SILVERMAN, S. J. Métodos de pesquisa em atividade física. $6^{\mathrm{a}}$ ed. Porto Alegre: Artmed, 2012.

VEIGA, I. P. A. Docência universitária na educação superior. In: RISTOFF, D.; SEVEGNANI, P. (Org.). Docência na educação superior. INEP: Instituto Nacional de Estudos e Pesquisas Educacionais Anísio Teixeira. Coleção Educação Superior em Debate, v. 5, 2006. p. 85-96.

VEIGA, R. F. Qualidade de vida no trabalho dos professores de educação física da rede municipal. 2013. Dissertação (Mestrado em Educação Física) - Universidade Federal de Pelotas, UFPEL, Pelotas, 2013.

WITTIZORECKI, E. S. Mudanças sociais e o trabalho docente do professorado de educação física na escola de ensino fundamental: um estudo na rede municipal de ensino de Porto Alegre. 2009. Tese (Doutorado em Educação Física) - Universidade Federal do Rio Grande do Sul, UFRGS, Rio Grande do Sul, 2009.

Recebido em: 27/08/2018

Revisado em: 24/01/2019

Aprovado em: 27/03/2019

Endereço para correspondência:

carolinebroch@yahoo.com.br

Caroline Broch

Universidade Estadual de Maringá

Av. Colombo, 5790

Zona 7 ,

87020-900 - Maringá - PR, Brasil. 